\title{
Principles of Rehabilitation and Reactivation
}

\author{
Christian R. Osadnik ${ }^{a, c, d}$ Fernanda M.M. Rodrigues ${ }^{a, b}$ \\ Carlos A. Camillo ${ }^{a, b}$ Matthias Loeckx ${ }^{a, b}$ Wim Janssens $^{b}$ Christophe Dooms ${ }^{b}$ \\ Thierry Troosters ${ }^{a, b}$ \\ ${ }^{a}$ Department of Rehabilitation Sciences, Katholieke Universiteit Leuven, and ${ }^{\mathrm{b}}$ Department of Respiratory \\ Diseases, University Hospitals KU Leuven, Leuven, Belgium; ' Department of Physiotherapy, Monash University, and \\ ${ }^{\mathrm{d}}$ Institute for Breathing and Sleep, Melbourne, Vic., Australia
}

\section{Key Words}

Chronic obstructive pulmonary disease - Physical activity .

Pulmonary rehabilitation

\begin{abstract}
Skeletal muscle dysfunction and physical inactivity are two clinically important features of a wide range of acute and chronic respiratory conditions. Optimisation of both of these features is important in order to improve physical function, prevent clinical deterioration and maximise community participation. One of the most potent and evidence-based interventions to address these physical deficits is pulmonary rehabilitation (PR). Whilst the majority of PR research has been conducted in patients with chronic obstructive pulmonary disease, there is widespread recognition that PR can benefit many other respiratory patient groups. These include patients with interstitial lung diseases, asthma, pulmonary hypertension, pre-/post-lung surgery (e.g. lung cancer, transplantation) and cystic fibrosis to name a few. Exercise training must be appropriately prescribed by a skilled healthcare professional with comprehensive knowledge of the pathology and physiology of these conditions, as well as a sound understanding of the exercise physiology and core principles of exercise prescription, monitoring and progression. It has also become increasingly recognised that people with
\end{abstract}

(C) 2015 S. Karger AG, Basel

0025-7931/15/0891-0002\$39.50/0 respiratory conditions, particularly those with chronic disease, are considerably less active than those of good health. PR should therefore aim to induce behavioural change to facilitate the adoption and maintenance of an active lifestyle. In addition, PR should pay attention to the psychological well-being of patients and self-management of their lung disease in all its aspects. To that end, multidisciplinary individualised programs should be offered. This review sets the scene of PR principles for a series of papers that will focus on specific diseases other than chronic obstructive pulmonary disease where rehabilitation may offer a clinically important aspect of care over and above conventional pharmacological treatment.

C 2015 S. Karger AG, Basel

\section{Introduction}

Pulmonary rehabilitation (PR) has become an evidence-based therapy for patients with respiratory disorders [1]. It has also made its way into disease-specific guidelines for treatment, but has received particular attention in patients with chronic obstructive pulmonary disease (COPD). This series in the journal will make it clear that comprehensive PR is of benefit well beyond patients with COPD. PR primarily aims to (1) target the

\section{KARGER 125}

E-Mail karger@karger.com www.karger.com/res
Prof. Dr. Thierry Troosters

Department of Rehabilitation Sciences and Respiratory Division

UZ Gasthuisberg, O\&N1, Box 706

Herestraat 49, BE-3000 Leuven (Belgium)

E-Mail Thierry.troosters@med.kuleuven.be 
non-respiratory (extrapulmonary) consequences of respiratory diseases, (2) ensure patients learn how to optimally manage their disease and (3) provide patients with the skills to lead a healthy life in terms of physical activity (PA), nutrition and emotional and psychological well-being. These aspects are most relevant in many chronic lung diseases (e.g. interstitial lung diseases, pulmonary hypertension, cystic fibrosis) and in acute respiratory conditions with chronic consequences (e.g. post-ICU, postlung cancer). These conditions share the common theme that patient morbidity is often larger than that of the respiratory involvement alone. Muscle dysfunction, for example, is well documented in COPD [2], but is also important in cystic fibrosis [3], pulmonary fibrosis [4], pulmonary hypertension [5] and in patients after an intensive care admission [6]. Similarly, depressive symptoms and social isolation are common in many respiratory diseases. An important underlying driver of these non-pulmonary consequences of respiratory disorders is physical inactivity. Again, this is well studied in COPD [7], but its importance is also recognised in other respiratory disease areas [8-10]. These are just some of the clear anchor points for rehabilitation interventions.

In this article the general principles of rehabilitation will be discussed in a broad respiratory disease context. Specific emphasis will be on providing a framework for rehabilitation and, in particular, exercise training and reactivation of patients. Other dimensions of the rehabilitation process and some general principles of organisation and access will also be discussed. Further reviews in this series will elaborate on the specific modifications of rehabilitation for specific respiratory diseases. Altogether this series aims to provide the clinician with awareness of the importance of $\mathrm{PR}$ for most patients with respiratory diseases and has the ambition to make each clinician read the series to reflect on the opportunities for rehabilitation in their specific clinical setting for their specific patient population. This series comes timely as a recent survey highlighted the relatively poor uptake of PR in general, but particularly for patients suffering from diseases other than COPD [11]. Whereas $97 \%$ of the programs had referrals of patients with COPD, only $74 \%$ had referrals for restrictive lung disease (including interstitial lung disease and thoracic wall diseases), and $71.9 \%$ for asthma or postthoracic surgery. These percentages were much lower for cystic fibrosis, pulmonary hypertension and other respiratory conditions [11]. This highlights the need to provide further insight into the specific benefits of rehabilitation for these patient groups and outlines how these programs could be organised.

Principles of Rehabilitation and Reactivation

\section{Principles of Exercise Training}

Exercise training is now widely considered a fundamental component of best practice medicine across an ever-growing list of chronic disease conditions. It can be applied during early or late disease stages and during periods of disease stability or acute unwellness. Common aims of PR include optimisation of physical function, improvement of symptoms and quality of life, and a reduction of healthcare utilisation in patients with excessive use. In COPD, these aims are supported by high-quality, level I evidence. The state of the art in diseases other than COPD is less developed. Nevertheless, the rationale for similar effects is surely present and a summary of studies and recommendations for specific disease groups was provided in the recent ATS/ERS PR statement [1], which demonstrates positive effects irrespective of underlying pathology [12-18]. With the exception of rapidly progressive diseases, like interstitial pulmonary fibrosis, where the exercise program can be complicated by disease progression, differences in the disease-specific magnitudes of response are unlikely to be attributable to the underlying pathology. Rather, they are likely to be partly explained by variation in training intensity, duration and frequency unique to the needs of that particular patient group. For example, lower exercise intensity is recommended for individuals with pulmonary hypertension or some patients awaiting lung transplantation $[1,19]$.

Exercise training involves a set of planned, structured and repetitive activities that aim to achieve specific training goals (e.g. improvement in strength, endurance or aerobic capacity/fitness). It differs to PA by its specific intent to improve health and/or fitness, and its stimulus being generally greater in intensity and duration than that of usual daily activities. Exercise training in the presence of respiratory dysfunction is reliant upon similar physiological mechanisms as those of other disease groups and of good health, as well as the same fundamental principles of exercise training. These include consideration of the frequency, intensity, type and timing of exercise (the 'FITT' principles; table 1). Exercise training should also be prescribed with due consideration of the principles of overload and progression, specificity and reversibility. These latter three principles are discussed further.

\section{Overload and Progression}

In order to improve skeletal muscle and/or cardiovascular function, these systems need to be 'overloaded' on a regular basis, without causing permanent injury. Several studies confirm larger physiological benefits of exer- 
Table 1. Overview of the 'FITT' principles of exercise training [20]

Frequency (how often to train)

Refers to the number of training sessions performed in a given time frame. In pulmonary rehabilitation, this is typically a minimum of 2-3 sessions per week. When prescribing exercise, particularly for individuals with respiratory dysfunction and skeletal muscle weakness, consideration must be given to the time afforded between sessions in order ensure adequate resting and recovery of skeletal muscles. This is particularly relevant when undertaking resistance training

Intensity (how hard to train)

Refers to the prescribed difficulty at which an individual trains. Exercise intensity is related to energy expenditure (the greater the intensity, the greater the energy expended), and is usually prescribed by a skilled healthcare professional from a baseline maximal exercise test. Intensity can be monitored objectively (e.g. via heart rate monitoring) or subjectively (e.g. via selfratings of perceived exertion)

Type (which modality to train)

Refers to the nature of the exercise training program. Common examples include interval or constant training. Decisions

regarding the type of training may be influenced by patient goals, exercise tolerance (ability to tolerate prolonged bouts of exercise) or training intensity (higher intensities may require more rests/ intervals)

Timing (how long to train)

Refers to the duration for which exercise training is sustained. Most PR programs are sustained for a minimum of 8 weeks in order to achieve significant improvements in whole body endurance and skeletal muscle strength

cise training in respiratory disease when exercise training was performed at a higher rather than lower intensity [21-24]. This does not preclude lower-intensity exercise training as effective at improving disabling respiratory symptoms and health-related quality of life [25]. The mechanisms through which low-intensity training works is nevertheless likely to be different than through alterations in muscle function. Rather, improved movement efficiency causing desensitisation to dyspnoea may explain its (more limited) efficacy. In COPD, patients who experienced significant skeletal muscle fatigue at completion of an exercise training session - a sign of overload - have shown better effects of an exercise training program [26, 27], again confirming that general training principles also apply in patients with respiratory disease. Overload is accomplished by altering one or more aspects of the training program. In respiratory disease, this most commonly involves increasing training load (intensity and/or repetitions), but may also include adjustments to movement velocity, reductions in recovery time or increases in training frequency (less common) [28]. For the cardiovascular system, exercise is recommended to be performed at an intensity between 40 and $85 \%$ of $\mathrm{VO}_{2}$ reserve or heart rate $_{\max }$ reserve, with lower values (40-50\% $\mathrm{VO}_{2}$ reserve) advised for adults who are quite unfit [20]. In patients with a ventilatory or gas exchange limitation to exercise, appropriate exercise intensities are usually obtained at symptom scores of 3-4 on a modified Borg dyspnoea scale (range $0-10$ ) or $12-13$ on a Borg rating of perceived exertion scale (range 6-20). For resistance training, loads corresponding to $50-85 \%$ of a maximum voluntary contraction are recommended [20].

\section{Specificity}

Clinicians need to consider that exercise training renders generally highly specific exercise training effects. With walking training for example, walking activities will improve more markedly than cycling exercise capacity. Training of the upper limbs will have little effect on lower limb or whole body exercise capacity [29-31]. Interestingly, even the type of activation of the muscle during the training and the observed results after training are specific. Arm ergometer training, for example, will only have marginal effects on more functional upper limb tasks and vice versa [32].

It should be noted that the transfer of training effects may be larger in frail elderly patients or those who are unwell compared to healthy fit young people as these patients start off with poor cardiorespiratory and/or skeletal muscle function. This transfer of training effects has been demonstrated in patients with COPD, where improvements in walking capacity have been observed following resistance training $[33,34]$. In the elderly, resistance training has also been shown to improve skeletal muscle oxidative capacity [35] - an effect not observed in young healthy subjects.

\section{Reversibility}

Benefits of exercise training wear off once a training stimulus is interrupted. This is as true for athletes as it is for respiratory patients, with several studies of patients with chronic respiratory disease demonstrating a loss of benefit up to 12 months following PR cessation [36-38]. The precise mechanism(s) explaining this functional decline is not well understood and is likely multifactorial. In individuals with respiratory disease, it is compelling to speculate that a lack of PA could be an important driver of the loss of training-related gains, particularly given their considerably lower levels of PA compared to healthy 
matched controls [39-41]. Other factors that may contribute to the loss of these benefits are exacerbations and disease progression.

\section{Exercise Limitations}

Exercise training is typically prescribed based on the exercise limitation in stable patients. Exercise may be limited by the cardiovascular system, the ventilatory system, the gas exchange system or the skeletal muscle itself. The training program can be adapted to these limitations by using interval training, small muscle group training or non-invasive mechanical ventilation in more ventilatory-limited patients. Oxygen therapy can be used in patients with a pulmonary gas exchange limitation and severe desaturation during exercise. Resistance training can be applied in people whose exercise performance is limited by skeletal muscle weakness. Inspiratory muscle training can be added in patients where weakness of the inspiratory muscles may limit exercise performance. The cause of the exercise limitations may differ in the acutely unwell state compared to the stable disease state. This is understandable when one considers the significant pathophysiological (respiratory and peripheral muscle) worsening that occurs during these episodes. Exercise training strategies may need to be modified in order to minimise the ventilatory burden. Several options for targeting this patient group have emerged in clinical practice, including changing exercise from active, volitional whole body training (e.g. cycling, walking) [42] to resistance training involving smaller muscle groups [43] or passive, non-volitional modalities (neuromuscular electrical stimulation) [44]. The physiological and exercise prescription principles are assumed to be equally applicable during periods of hospitalisation; however, it is important to note that the evidence base relating to this disease phase is far less developed than that of the stable state. Furthermore, specific attention needs to be given to select patient groups who may be at increased risk of adverse events or injury during this period of their disease, e.g. patients on high-dose corticosteroids who may have increased osteoporosis risk or those on fluoroquinolones (a class of antimicrobials) who may be at risk of tendon rupture $[45,46]$.

Despite being a recommended form of therapy for all patients with COPD, it is acknowledged that PR may be potentially unsuitable for a minority of individuals with diseases other than COPD [1]. Indeed, exercise training modalities and training intensities need to be adapted to

Principles of Rehabilitation and

Reactivation accommodate patients' exercise limitations. Other components of the program, including self-management strategies and education, should also be tailored on an individual needs basis rather than a 'one size fits all' model.

\section{Overview of Typical Exercise Programs}

PR has most recently been defined as 'a comprehensive intervention based on a thorough patient assessment followed by patient-tailored therapies, which include, but are not limited to, exercise training, education, and behavior change...' [1]. In terms of exercise training, the core component of PR, tailored therapy can only occur following a thorough assessment of exercise capacity. This involves evaluation of aerobic endurance and muscle strength [2]. In PR, supervised exercise training typically takes place on at least 2-3 weekdays, supported by unsupervised home exercise on other days to amount to 5 days training per week maximally. It is important that moments of rest are built in for the muscle and other body structures to recover from the exercise-induced stress. An overview of the main training components of PR is outlined below.

Aerobic training involves sustained, moderate- to high-intensity, repetitive activities that utilise muscles of relatively large mass to render a relatively high cardiorespiratory load. Typical exercises are (brisk) walking or jogging, and cycling or aquatic exercises. These exercises can be performed either continuously or in bouts (intermittently). Although both (continuous or interval) have similar results, interval exercise affords increased opportunity for progression of intensity, particularly in the presence of ventilatory limitation, and is commonly perceived as more comfortable by patients. Exercises are commonly progressed to a target of $20 \mathrm{~min}$, where able, guided by self-rated dyspnoea scores (e.g. modified Borg dyspnoea scale).

Resistance training involves high-resistance, low-repetition exercise to improve strength, or lower-resistance, higher-repetition exercise to improve endurance. Common examples include free weights (e.g. bicep curls, lateral flies) and exercise machines (e.g. seated leg press, chest press). Dosage is usually prescribed according to number of repetitions and degree of resistance and progression achieved by increasing resistance/load (for strength) or repetitions/duration (for endurance). Resistance training should target important muscle groups, including those with large muscle mass (e.g. quadriceps, 
gluteals), those with multi-joint function (e.g. gastrocnemius, biceps, hamstrings) and those with important roles for the conduct of common activities of daily living (e.g. chest, shoulders to improve showering or cleaning).

The initial training load is typically set according to a patient's baseline maximal capacity. For aerobic training, this is usually determined from a maximal (or near maximal) walking or cycling test. For resistance training, this is usually prescribed from a 1-repetition maximal contraction test. Progression of the training intensity can be done using objective measurements (e.g. \% maximal work rate) or subjectively (e.g. perceived dyspnoea or exertion) $[1,20]$.

Intrasession intensity progression may depend on an individual's capacity to progress [1] or risk of potential side effects (e.g. exercise-induced bronchospasm in asth$\mathrm{ma})$. Progression is typically mostly linear, but recently in COPD, non-linear periodisation training has been applied successfully [47]. In this concept, adapted from sports training, volume is increased by altering intensity and duration. Consideration must also be given to appropriate add-on therapies such as oxygen supplementation for patients with appropriate indications (e.g. gas exchange limitation, pulmonary hypertension or interstitial lung diseases). Monitoring of patients via use of pulse oximeters, heart rate, or perceived exertion or dyspnoea scales during training must also be adapted to suit individual needs (e.g. in pulmonary hypertension) to ensure the safe attainment of individual goals in a disease-specific context.

\section{Rehabilitation beyond Exercise Training}

The 2013 ATS/ERS statement on PR promotes consideration of goals beyond improvements in exercise capacity [1]. This may include factors such as maximising community function (i.e. participation) and PA, minimising healthcare utilisation, optimisation of self-management skills and facilitation of long-term sustainable behaviour change. Comprehensive PR programs must therefore involve more than just exercise. Whereas the benefits of exercise training are relatively straightforward to obtain if an exercise program is properly delivered, the effectiveness of rehabilitation to obtain 'sustainable behaviour change' is much less certain. Nevertheless, efforts should be taken to tackle other aspects of improvement beyond pure exercise physiology all the more since exercise benefits without a healthier lifestyle are short lived. Examples of these other components relevant to most chronic re- spiratory conditions are education, interdisciplinary support, self-management and behaviour modification.

\section{Education}

Education may comprise formal or informal educational sessions covering topics such as disease knowledge, medication use, how to exercise and symptom management. Education aims to promote knowledge and confidence to optimise patient care [48] and self-management. It is a common component of PR programs; however, its clinical benefit in addition to exercise training is questionable [49], perhaps due to a failure of teaching methods (commonly didactic in nature) to address the adult learning styles of this patient group. In addition, many of the education topics are disease population specific and cannot be simply extrapolated from COPD programs.

\section{Interdisciplinary Support}

The exercise component of PR is typically facilitated by physiotherapists or specialists in exercise therapy; however, programs commonly involve other allied health and medical professions such as a chest physician, respiratory nurses, occupational therapists, dieticians, speech therapists, exercise physiologists and social workers. This support network, often extended to the home network by involving healthcare workers in primary care and general practitioners, is an important feature of holistic PR. Large networks are frequently lacking in community- or homebased programs, but technically could be set up with good collaboration between reference centres and community or primary care rehabilitation facilities in order to optimise access with minimal loss of quality. Such collaborations have been documented in the US (between National Emphysema Treatment Trial reference centres and satellite centres) [18] and the Netherlands (between community- and hospital-based allied health professionals; the 'INTERCOM' project) [50]. For rare respiratory conditions, it seems imperative to set up such collaborations to streamline rehabilitation care between reference and rehabilitation centres.

\section{Self-Management}

Many individuals with chronic respiratory disease experience difficulty managing symptoms, medications or anxiety/depression, or lack knowledge of how to respond to changes from their stable disease state. Action plans are one example of a self-management strategy that can be implemented and reinforced during the time spent in the supported environment of a PR program. These are particularly common in conditions such as asthma and 
Table 2. Common examples of problematic behaviours and possibilities for assessment or assistance in a comprehensive interdisciplinary PR program

\begin{tabular}{ll}
\hline Problematic behaviour & Possible source of interdisciplinary assistance \\
\hline Physical inactivity & Physiotherapy (coaching, feedback, activity action plans) \\
Poor diet & Dietician (meal plans, nutritional supplements, support) \\
Poor medication adherence & Pharmacologist, nurse (education, medication packs) \\
Smoking & Smoking cessation team (nurse, physiotherapist, psychologist), counselling \\
Anxiety/depression & Psychologist, social worker support \\
\hline
\end{tabular}

COPD. Other aspects of self-management such as relaxation techniques or airway clearance techniques may be taught via formal or informal sessions. Although selfmanagement strategies may be a relevant addition to rehabilitation in conditions beyond COPD (e.g. cystic fibrosis), the effectiveness of such programs remains uncertain [51].

\section{Behaviour Modification}

A critical priority of many rehabilitation programs is the need to foster sustainable, health-promoting behaviours that extend well beyond program completion. This is particularly important where reversible risk factors or comorbidities such as obesity, poor nutrition, smoking, medication non-adherence or physical inactivity are present. Assessment of problematic behaviour, and agreement on priorities in terms of behaviour changes should be made with all patients. Common examples of problematic behaviours for respiratory patients and possibilities for assessment or assistance in a comprehensive interdisciplinary PR program are presented in table 2. Behaviour modification may be informally addressed through ad hoc conversation and consultation with the interdisciplinary team, or formally addressed through interventions based upon principles of motivational interviewing and goal setting. The importance of promoting physically active lifestyles (or 'reactivation') during and after PR is becoming increasingly recognised and deserves specific attention.

\section{Reactivation (PA): The Challenge of Rehabilitation}

Whilst conventional PR is associated with significant improvements in exercise capacity, it is associated with minimal change (a few minutes) in daily PA levels [52, 53]. This occurs as these two factors are only intuitively linked and demonstrate moderate correlations at best [7]
It is currently unknown (1) how much PA (in terms of amount and intensity) is needed in the prevention of nonrespiratory consequences of pulmonary disease and (2) how much PA is needed to maintain the benefits as long as possible. The World Health Organization (WHO) recommends all adults undertake at least 150 min of moderate-intensity aerobic activity per week, such as walking, to maintain a healthy lifestyle [54]. This highlights a significant challenge of PR: becoming physically active is not equivalent to exercising for a defined number of weeks. It involves more than physiology and is a complex process involving behaviour and an interaction between individuals and their environment $[55,56]$.

\section{Principles of Reactivation}

Best practice strategies to improve PA levels differ from best practice to improve exercise capacity, but the strategies are complementary. Whereas exercise strategies focus on physiological principles, strategies to increase PA follow processes that enhance motivation and self-efficacy, alleviate barriers in daily life, and provide opportunities to be or become active. Exercise training may be an enabler for PA, but when delivered without a specific focus on changing PA, is unlikely to be sufficient to substantially and sustainably enhance PA levels. There is no reason to believe this would differ in other respiratory conditions. Recently, a statement on PA in COPD was endorsed and published by the European Respiratory Society [7]. Evidence-based recommendations could not be made, but several strategies were discussed as promising to improve activity levels in individual patients. These strategies likely apply beyond COPD, but remain untested. Examples of promising strategies include counselling $[57,58]$, pedometer feedback [59] and the adoption of exercise forms that are practical and enjoyable to implement in daily life (e.g. Nordic walking). Modern technol- 


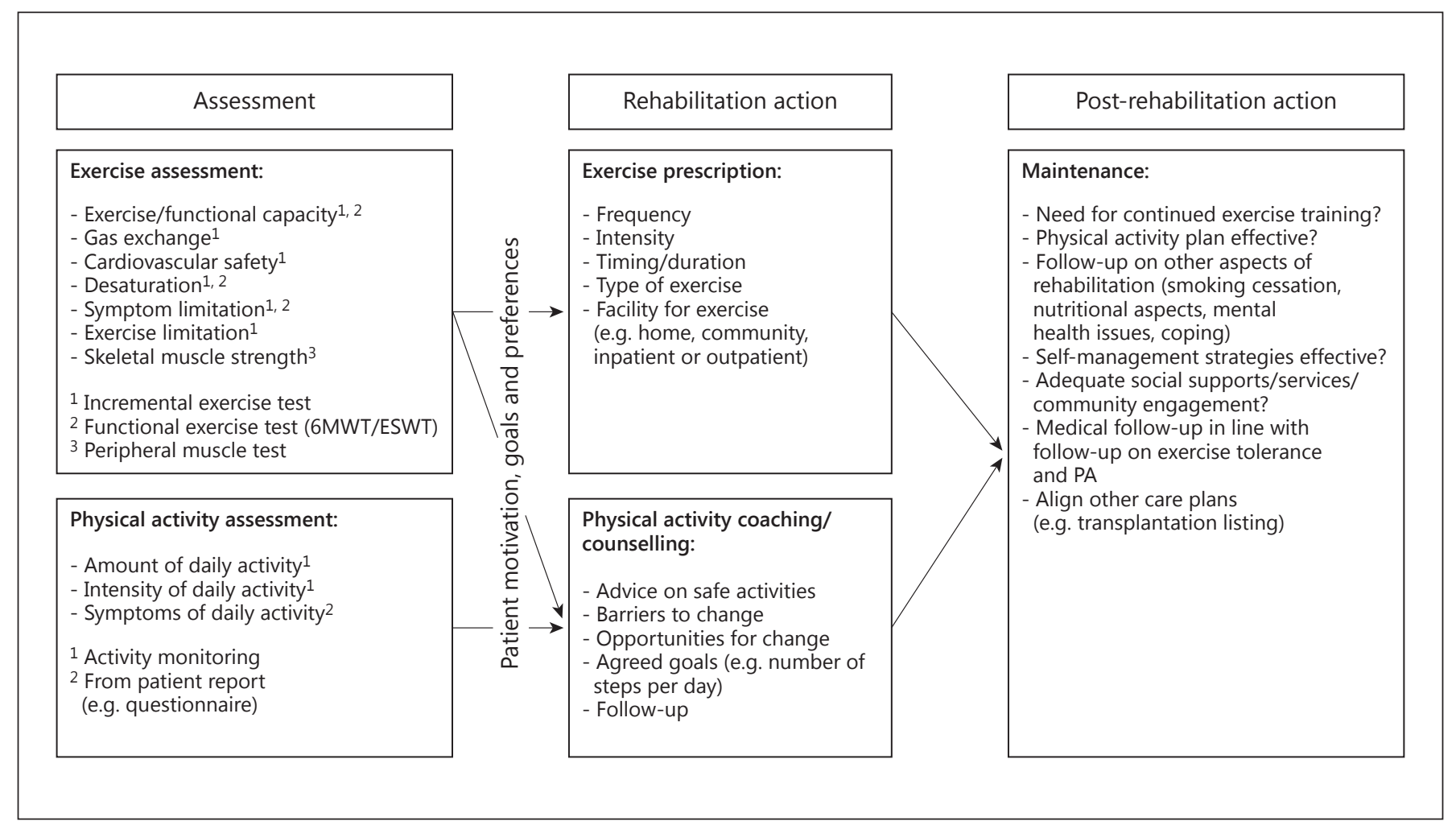

Fig. 1. Proposed model for comprehensive patient assessment and individualised physical rehabilitation and reactivation. ESWT $=$ Endurance shuttle walk test; $6 \mathrm{MWT}=$ Six-minute walk test.

ogy also allows us to support patients in this process of becoming more active through telecoaching and use of agreed goals and real-time feedback [60, 61]. An important consideration for such interventions, especially those applied during PR, is careful consideration of their effect on overall PR effectiveness.

In order to tailor the most appropriate therapy to individuals' specific rehabilitation needs, comprehensive assessment of exercise capacity, skeletal muscle function and PA should be undertaken prior to commencement of PR (fig. 1). It may only be then that the priority can shift from exercise training to altering PA behaviour. This is important, as PA, like exercise training, should be prescribed according to individual abilities and goals, as well as titrated within limits of safety. Proper assessment of the cardiovascular risks of exercise needs to be done prior to advising patients about PA, particularly for non-COPD respiratory diseases that may associate with brisk desaturation rather than airflow obstruction (e.g. pulmonary hypertension, interstitial lung diseases). At a public health level, the widespread adoption of physically active lifestyles will involve efforts far beyond opportunities afforded during rehabilitation programs. This will include significant reform at the level of health and government policy, society and culture, and the environment [56], from which patients with respiratory disease could eventually benefit.

\section{Rehabilitation Embedded in Global Patient Care}

PR can only be an effective intervention for those in need if it can be accessed. Unfortunately, there are far more people with respiratory disease than there are places in PR programs. Even when offered, not all patients choose to attend PR and many fail to attend until completion [62]. Barriers to rehabilitation participation such as patient disbelief of its effectiveness (which may be of even greater importance in non-COPD groups), transport [62], weather and lack of support $[63,64]$ can be challenging to overcome. Alternative models of care such 
as telerehabilitation, home-based rehabilitation or community-based group programs are therefore becoming increasingly viewed as options that are not just novel, but perhaps essential, particularly in regions with low population densities. Such approaches are, however, not yet widespread in clinical practice and may require significant investment of resources, support and/or technology. In addition, in less common diseases the rehabilitation may be challenging to supervise. Their effectiveness compared to conventional PR programs also largely remains undetermined.

Another important consideration for rehabilitation programs is the issue of how to maximise and sustain benefits obtained during the period of training. For example, high-level evidence demonstrates not only that significant improvements in exercise capacity can be achieved following PR in a variety of disease groups, but that rehabilitation cessation is frequently associated with a decline (or loss) of these effects over time (reversibility principle; see above). This may be less important for individuals requiring acute 'restorative' rehabilitation (e.g. post-ICU stay or during or after an exacerbation), but is a significant challenge for those with ongoing chronic diseases who may function at a level that is below that required to maintain health due to their respiratory symptoms (e.g. cystic fibrosis, bronchiectasis, interstitial lung disease). The most common method of maintaining benefit is enrolment of such individuals in maintenance programs, often with long-term follow-up. These generally comprise a similar structure to conventional exercise training programs, but typically involve reduced exercise supervision, reduced (or ceased) interprofessional education and a reduced number of scheduled sessions per week. Maintenance programs have been demonstrated to prevent the decline in exercise capacity in certain disease groups for periods of up to 12 months, although evidence is conflicting in COPD and, to the best of our knowledge, non-existent in other respiratory diseases. Ultimately, the final aim of rehabilitation programs for many individuals with chronic respiratory disease is self-management and re-integration, or maintenance or a role within the community. As physical inactivity is an important underlying driver of the many serious extrapulmonary consequences of respiratory disorders, achievement of such an aim may depend on the effectiveness of comprehensive rehabilitation strategies to facilitate ongoing attainment of recommended daily PA targets. This remains a priority area of future research.

In summary, evidence is emerging around the effectiveness of PR programs for patients with respiratory conditions beyond COPD. Although programmes may have the same architecture as for patients with COPD, the content needs to be individually tailored and based on proper assessment of the patient's needs. Active (often remote) collaboration between centres of reference and rehabilitation programs may be required to ensure expertise and accessibility are optimally combined in more rare respiratory conditions. The focus of programs for these patients, nevertheless, should be in line with the definition of PR, i.e. a program 'designed to improve the physical and psychological condition of people and to promote the long-term adherence to health-enhancing behaviors' [1].

\section{Financial Disclosure and Conflicts of Interest}

C.R.O. is a recipient of a European Respiratory Society Fellowship (LTRF 2014-3132), F.M.M.R. is a PhD fellow of CNPq/Brazil (249579/2013-8), C.A.C. is a $\mathrm{PhD}$ fellow of CNPq/Brazil (202425/2011-8) and T.T. is supported by Flemish Research Foundation (FWO No. G.0871.13).

\section{References}

1 Spruit MA, Singh SJ, Garvey C, ZuWallack R, Nici L, Rochester C, et al: An official American Thoracic Society/European Respiratory Society statement: key concepts and advances in pulmonary rehabilitation. Am J Respir Crit Care Med 2013; 188:e13-e64.

-2 Maltais F, Decramer M, Casaburi R, Barreiro E, Burelle Y, Debigare R, et al: An official American Thoracic Society/European Respiratory Society statement: update on limb muscle dysfunction in chronic obstructive pulmonary disease. Am J Respir Crit Care Med 2014;189:e15-e62.

Principles of Rehabilitation and Reactivation
3 Troosters T, Langer D, Vrijsen B, Segers J, Wouters K, Janssens W, et al: Skeletal muscle weakness, exercise tolerance and physical activity in adults with cystic fibrosis. Eur Respir J 2009;33:99-106.

$\checkmark 4$ Mendoza L, Gogali A, Shrikrishna D, Cavada G, Kemp SV, Natanek SA, et al: Quadriceps strength and endurance in fibrotic idiopathic interstitial pneumonia. Respirology 2014;19: 138-143.

5 Mainguy V, Maltais F, Saey D, Gagnon P, Martel S, Simon M, et al: Peripheral muscle dysfunction in idiopathic pulmonary arterial hypertension. Thorax 2010;65:113-117.
6 Hermans G, Van Mechelen H, Clerckx B, Vanhullebusch T, Mesotten D, Wilmer A, et al: Acute outcomes and 1-year mortality of intensive care unit-acquired weakness. A cohort study and propensity-matched analysis. Am J Respir Crit Care Med 2014;190:410-420.

7 Watz H, Pitta F, Rochester CL, Garcia-Aymerich J, ZuWallack R, Troosters T, et al: An official European Respiratory Society statement on physical activity in COPD. Eur Respir J 2014;44:1521-1537.

\section{Reactivation}


8 Pugh ME, Buchowski MS, Robbins IM, Newman JH, Hemnes AR: Physical activity limitation as measured by accelerometry in pulmonary arterial hypertension. Chest 2012;142: 1391-1398.

-9 Schneiderman JE, Wilkes DL, Atenafu EG, Nguyen T, Wells GD, Alarie N, et al: Longitudinal relationship between physical activity and lung health in patients with cystic fibrosis. Eur Respir J 2014;43:817-823.

10 Wallaert B, Monge E, Le Rouzic O, WemeauStervinou L, Salleron J, Grosbois JM: Physical activity in daily life of patients with fibrotic idiopathic interstitial pneumonia. Chest 2013;144:1652-1658.

-11 Spruit MA, Pitta F, Garvey C, ZuWallack RL, Roberts CM, Collins EG, et al: Differences in content and organisational aspects of pulmonary rehabilitation programmes. Eur Respir J 2014;43:1326-1337.

$\checkmark 12$ Grünig E, Ehlken N, Ghofrani A, Staehler G, Meyer FJ, Juenger J, et al: Effect of exercise and respiratory training on clinical progression and survival in patients with severe chronic pulmonary hypertension. Respiration 2011;81:394-401.

$\checkmark 13$ Holland A, Hill C: Physical training for interstitial lung disease. Cochrane Database Syst Rev 2008;4:CD006322.

14 Jones LW, Peddle CJ, Eves ND, Haykowsky MJ, Courneya KS, Mackey JR, et al: Effects of presurgical exercise training on cardiorespiratory fitness among patients undergoing thoracic surgery for malignant lung lesions. Cancer 2007;110:590-598.

15 Maury G, Langer D, Verleden G, Dupont L, Gosselink R, Decramer M, et al: Skeletal muscle force and functional exercise tolerance before and after lung transplantation: a cohort study. Am J Transplant 2008;8:1275-1281.

16 Mendes FA, Goncalves RC, Nunes MP, Saraiva-Romanholo BM, Cukier A, Stelmach R, et al: Effects of aerobic training on psychosocial morbidity and symptoms in patients with asthma: a randomized clinical trial. Chest 2010;138:331-337.

17 Ong HK, Lee AL, Hill CJ, Holland AE, Denehy L: Effects of pulmonary rehabilitation in bronchiectasis: a retrospective study. Chron Respir Dis 2011;8:21-30.

-18 Ries AL, Make BJ, Lee SM, Krasna MJ, Bartels $\mathrm{M}$, Crouch R, et al: The effects of pulmonary rehabilitation in the national emphysema treatment trial. Chest 2005;128:3799-3809.

19 Rochester CL, Fairburn C, Crouch RH: Pulmonary rehabilitation for respiratory disorders other than chronic obstructive pulmonary disease. Clin Chest Med 2014;35:369-389.

20 Garber CE, Blissmer B, Deschenes MR, Franklin BA, Lamonte MJ, Lee IM, et al: American College of Sports Medicine position stand. Quantity and quality of exercise for developing and maintaining cardiorespiratory, musculoskeletal, and neuromotor fitness in apparently healthy adults: guidance for prescribing exercise. Med Sci Sports Exerc 2011;43:1334-1359.
21 Bendstrup KE, Ingemann Jensen J, Holm S, Bengtsson B: Out-patient rehabilitation improves activities of daily living, quality of life and exercise tolerance in chronic obstructive pulmonary disease. Eur Respir J 1997;10: 2801-2806.

22 Casaburi R, Patessio A, Ioli F, Zanaboni S, Donner CF, Wasserman K: Reductions in exercise lactic acidosis and ventilation as a result of exercise training in patients with obstructive lung disease. Am Rev Respir Dis 1991; 143:9-18.

23 Gigliotti F, Coli C, Bianchi R, Romagnoli I, Lanini B, Binazzi B, et al: Exercise training improves exertional dyspnea in patients with COPD: evidence of the role of mechanical factors. Chest 2003;123:1794-1802.

24 Varga J, Porszasz J, Boda K, Casaburi R, Somfay A: Supervised high intensity continuous and interval training vs. self-paced training in COPD. Respir Med 2007;101:2297-2304.

25 Datta D, ZuWallack R: High versus low intensity exercise training in pulmonary rehabilitation: is more better? Chron Respir Dis 2004;1: 143-149.

26 Burtin C, Saey D, Saglam M, Langer D, Gosselink R, Janssens W, et al: Effectiveness of exercise training in patients with COPD: the role of muscle fatigue. Eur Respir J 2012;40: 338-344.

27 Mador MJ, Mogri M, Patel A: Contractile fatigue of the quadriceps muscle predicts improvement in exercise performance after pulmonary rehabilitation. J Cardiopulm Rehabil Prev 2014;34:54-61.

28 Kraemer WJ, Ratamess NA: Fundamentals of resistance training: progression and exercise prescription. Med Sci Sports Exerc 2004;36: 674-688.

29 Janaudis-Ferreira T, Hill K, Goldstein R, Wadell K, Brooks D: Arm exercise training in patients with chronic obstructive pulmonary disease: a systematic review. J Cardiopulm Rehabil Prev 2009;29:277-283.

30 Janaudis-Ferreira T, Hill K, Goldstein RS, Robles-Ribeiro P, Beauchamp MK, Dolmage TE, et al: Resistance arm training in patients with COPD: a randomized controlled trial. Chest 2011;139:151-158.

-31 Ries AL, Ellis B, Hawkins RW: Upper extremity exercise training in chronic obstructive pulmonary disease. Chest 1988;93:688-692.

- 32 Martinez FJ, Vogel PD, Dupont DN, Stanopoulos I, Gray A, Beamis JF: Supported arm exercise versus unsupported arm exercise in the rehabilitation of patients with severe chronic airflow obstruction. Chest 1993;103: 1397-1402.

33 O'Shea SD, Taylor NF, Paratz J: Peripheral muscle strength training in COPD: a systematic review. Chest 2004;126:903-914.

34 Spruit MA, Gosselink R, Troosters T, De Paepe K, Decramer M: Resistance versus endurance training in patients with COPD and peripheral muscle weakness. Eur Respir J 2002;19:1072-1078.
35 Sala E, Roca J, Marrades RM, Alonso J, Gonzalez De Suso JM, Moreno A, et al: Effects of endurance training on skeletal muscle bioenergetics in chronic obstructive pulmonary disease. Am J Respir Crit Care Med 1999;159: 1726-1734.

36 Griffiths TL, Burr ML, Campbell IA, LewisJenkins V, Mullins J, Shiels K, et al: Results at 1 year of outpatient multidisciplinary pulmonary rehabilitation: a randomised controlled trial. Lancet 2000;355:362-368.

- 37 Holland AE, Hill CJ, Conron M, Munro P, McDonald CF: Short term improvement in exercise capacity and symptoms following exercise training in interstitial lung disease. Thorax 2008;63:549-554.

38 Ries AL, Kaplan RM, Limberg TM, Prewitt LM: Effects of pulmonary rehabilitation on physiologic and psychosocial outcomes in patients with chronic obstructive pulmonary disease. Ann Intern Med 1995;122:823-832.

39 Pitta F, Troosters T, Spruit MA, Probst VS, Decramer M, Gosselink R: Characteristics of physical activities in daily life in chronic obstructive pulmonary disease. Am J Respir Crit Care Med 2005;171:972-977.

40 Troosters T, Gosselink R, Janssens W, Decramer M: Exercise training and pulmonary rehabilitation: new insights and remaining challenges. Eur Respir Rev 2010;19:24-29.

41 Watz H, Waschki B, Meyer T, Magnussen H: Physical activity in patients with COPD. Eur Respir J 2009;33:262-272.

42 Troosters T, Gosselink R, Decramer M: Shortand long-term effects of outpatient rehabilitation in patients with chronic obstructive pulmonary disease: a randomized trial. Am J Med 2000;109:207-212.

43 Troosters T, Probst VS, Crul T, Pitta F, GayanRamirez G, Decramer M, et al: Resistance training prevents deterioration in quadriceps muscle function during acute exacerbations of chronic obstructive pulmonary disease. Am J Respir Crit Care Med 2010;181:1072-1077.

44 Chaplin EJ, Houchen L, Greening NJ, Harvey-Dunstan T, Morgan MD, Steiner MC, et al: Neuromuscular stimulation of quadriceps in patients hospitalised during an exacerbation of COPD: a comparison of low $(35 \mathrm{~Hz})$ and high $(50 \mathrm{~Hz})$ frequencies. Physiother Res Int 2013;18:148-156.

45 Khaliq Y, Zhanel GG: Fluoroquinolone-associated tendinopathy: a critical review of the literature. Clin Infect Dis 2003;36:1404-1410.

46 Lewis TG: A rare case of ciprofloxacin-induced bilateral rupture of the Achilles tendon. BMJCase Rep 2009;2009: pii:bcr08.2008.0697.

$\checkmark 47$ Klijn P, van Keimpema A, Legemaat M, Gosselink R, van Stel H: Nonlinear exercise training in advanced chronic obstructive pulmonary disease is superior to traditional exercise training. A randomized trial. Am J Respir Crit Care Med 2013;188:193-200.

48 Bourbeau J, Nault D, Dang-Tan T: Self-management and behaviour modification in COPD. Patient Educ Couns 2004;52:271277. 
49 Blackstock FC, Webster KE, McDonald CF, Hill CJ: Comparable improvements achieved in chronic obstructive pulmonary disease through pulmonary rehabilitation with and without a structured educational intervention: a randomized controlled trial. Respirology 2014;19:193-202.

50 van Wetering CR, Hoogendoorn M, Mol SJ, Rutten-van Molken MP, Schols AM: Shortand long-term efficacy of a community-based COPD management programme in less advanced COPD: a randomised controlled trial. Thorax 2010;65:7-13.

-51 Savage E, Beirne PV, Ni Chroinin M, Duff A, Fitzgerald T, Farrell D: Self-management education for cystic fibrosis. Cochrane Database Syst Rev 2014;9:CD007641.

52 Cindy Ng LW, Mackney J, Jenkins S, Hill K: Does exercise training change physical activity in people with COPD? A systematic review and meta-analysis. Chron Respir Dis 2012;9: $17-26$.

53 Troosters T, Sciurba F, Battaglia S, Langer D, Valluri SR, Martino L, et al: Physical inactivity in patients with COPD, a controlled multicenter pilot-study. Respir Med 2010;104: 1005-1011.
54 World Health Organization: Global recommendation on physical activity for health 2010. http://whqlibdoc.who.int/publications/2010/9789241599979_eng.pdf?ua=1.

55 Casaburi R: Activity promotion: a paradigm shift for chronic obstructive pulmonary disease therapeutics. Proc Am Thorac Soc 2011; 8:334-337.

56 Das P, Horton R: Rethinking our approach to physical activity. Lancet 2012;380:189-190.

57 de Blok BM, de Greef MH, ten Hacken NH, Sprenger SR, Postema K, Wempe JB: The effects of a lifestyle physical activity counseling program with feedback of a pedometer during pulmonary rehabilitation in patients with COPD: a pilot study. Patient Educ Couns 2006;61:48-55.

58 Hospes G, Bossenbroek L, Ten Hacken NH, van Hengel P, de Greef MH: Enhancement of daily physical activity increases physical fitness of outclinic COPD patients: results of an exercise counseling program. Patient Educ Couns 2009;75:274-278.

59 Mendoza L, Horta P, Espinoza J, Aguilera M, Balmaceda N, Castro A, et al: Pedometers to enhance physical activity in COPD: a randomised controlled trial. Eur Respir J 2014, Epub ahead of print.
60 Moy ML, Weston NA, Wilson EJ, Hess ML, Richardson CR: A pilot study of an Internet walking program and pedometer in COPD. Respir Med 2012;106:1342-1350.

61 Steele BG, Belza B, Cain KC, Coppersmith J, Lakshminarayan S, Howard J, et al: A randomized clinical trial of an activity and exercise adherence intervention in chronic pulmonary disease. Arch Phys Med Rehabil 2008;89:404-412.

62 Keating A, Lee A, Holland AE: What prevents people with chronic obstructive pulmonary disease from attending pulmonary rehabilitation? A systematic review. Chron Respir Dis 2011;8:89-99.

63 Desveaux L, Rolfe D, Beauchamp M, Goldstein R, Brooks D: Participant experiences of a community-based maintenance program post-pulmonary rehabilitation. Chron Respir Dis 2014;11:23-30.

64 Goldstein RS, Hill K, Brooks D, Dolmage TE: Pulmonary rehabilitation: a review of the recent literature. Chest 2012;142:738-749. 